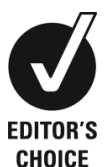

CHOICE

\title{
Two typical cases of pseudoankylosis of the jaw: same treatment, different outcome
}

\author{
Fabiana Allevi, ${ }^{1}$ Valeria Battista, ${ }_{1}^{1}$ Laura Moneghini, ${ }^{2}$ Federico Biglioli ${ }^{1}$
}

${ }^{1}$ Department of Maxillo Facial Surgery, San Paolo Hospital, University of Milan, Milan, Italy 2Department of Surgical Pathology, San Paolo Hospital, University of Milan, Milan, Italy

\section{Correspondence to}

Dr Fabiana Allevi,

fabiana.allevi@gmail.com

Accepted 19 July 2015
CrossMark

\footnotetext{
To cite: Allevi F, Battista $\mathrm{V}$, Moneghini L, et al. BMJ Case Rep Published online: [please include Day Month Year] doi:10.1136/bcr-2015210099
}

\section{SUMMARY}

Pseudoankylosis of the temporomandibular joint is a rare, extra-articular form of ankylosis of the jaw. It is characterised by limited mandibular movement caused by an extrinsic condition of the joint leading to fusion between the coronoid process and temporal, zygomatic or maxillary bone. Pseudoankylosis is less frequent than the intracapsular form. Extracapsular ankylosis can be congenital or acquired; approximately $70 \%$ of cases are associated with trauma. A CT scan is usually requested to achieve a diagnosis. CT can detect bony fusion, thus differentiating pseudoankylosis from true ankylosis. Once symptomatic bone ankylosis is diagnosed, surgery with postoperative physiotherapy is the recommended treatment. The ankylotic bone is removed together with the coronoid process and the mouth is forced open under general anaesthesia. Two cases of post-traumatic pseudoankylosis of the jaw treated with bilateral coronoidectomy and postoperative physiotherapy are described.

\section{BACKGROUND}

Pseudoankylosis of the temporomandibular joint (TMJ) is a rare condition that causes inability to open the mouth. It is characterised by mandibular hypomobility caused by an extrinsic condition of the joint that results in fusion between the coronoid process and temporal, ${ }^{1}$ zygomatic ${ }^{2}{ }^{3}$ or maxillary bone. ${ }^{4} 5$

Pseudoankylosis of the TMJ is less frequent than intracapsular ankylosis. Exact figures for the incidence of ankyloses and pseudoankyloses of the TMJ in the general population are not available in the literature. It is even more difficult to compare the incidence of ankyloses and pseudoankyloses given the lack of common definitions in most articles. ${ }^{6}$ Nevertheless, it is known that extracapsular ankylosis can be congenital or acquired and complicates up to $0.6 \%$ of undiagnosed zygomatic fractures. ${ }^{7}$ Approximately $88 \%$ of cases of pseudoankylosis are associated with a history of trauma. ${ }^{8}$ Traumas, with or without fracture, including surgery, can induce the formation of fibrous/ scar adhesion in the temporal and masseter muscles. ${ }^{9}$ Diagnosis is based on clinical and radiological evaluations.

Pseudoankylosis is clinically characterised by limited mandibular movement with no pain. Orthopantomography can identify the presence of elongated coronoids, condyle tumours and TMJ ankylosis. However, a CT scan is usually requested as it can detect bony fusion, thus differentiating pseudoankylosis from true ankylosis. Because CT scans do not provide enough information about soft tissue disorders, MRI may be indicated when fibrous tissue formation is suspected. ${ }^{10}$ Once diagnosed, symptomatic bone ankylosis can be treated with surgery (usually by coronoidectomy) or conservatively (with forced mouth opening). ${ }^{10-12}$

A case of coronoid-zygomatic arch ankylosis and a case of coronoid-temporal bone ankylosis are reported.

\section{CASE PRESENTATION \\ Case A}

A 32-year-old woman was referred to our unit for limited jaw movement. The patient had been involved in a road trauma accident at 22 years of age, resulting in an ascending aortic rupture, fractures of the left forearm, humerus, scapula and right fibula, right pneumothorax, and spleen and liver contusions. She underwent multiple surgical procedures while she was in a drug-induced coma. In addition, she had displaced the left angle and right condylar and coronoid processes of the mandible, which were treated with open reduction and internal fixation with one plate on the angle and rigid intermaxillary fixation through arch bars for 23 days. No physiotherapy was possible during the coma.

Ten years later, the patient requested a consultation in our centre. Interincisal mouth opening was $15 \mathrm{~mm}$, with a $3 \mathrm{~mm}$ deviation toward the injured side of the jaw. Bilateral and protrusive jaw movements were reduced. She had a first class normal occlusion. The patient did not complain of pain, either spontaneous or induced (figure 1).

\section{Case B}

A 37-year-old male patient was referred to our department in 2012 because of limited mandibular movement that had been worsening since 1996

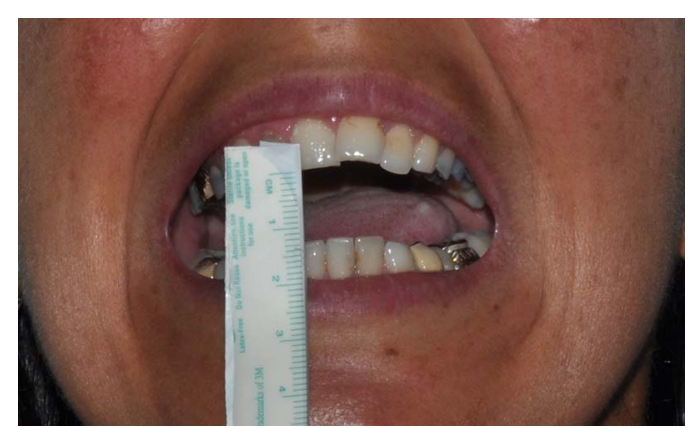

Figure 1 Preoperative photograph showing severely limited maximal mouth opening in patient $A$. 


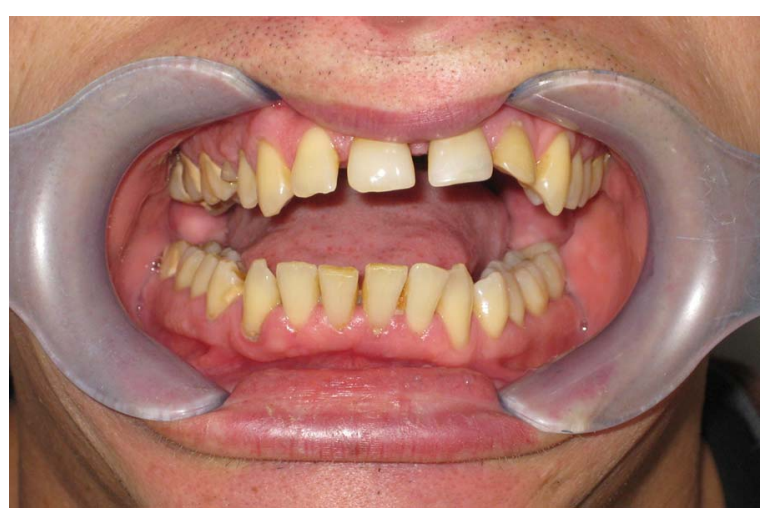

Figure 2 Preoperative photograph showing severely limited maximal mouth opening in patient $B$.

after a craniofacial trauma. After the event, he demonstrated oedema of the upper and middle third of the right side of his face. No facial fractures were identified. Because of the pain due to the trauma, the patient had limited ability to open his mouth immediately after the traumatic event.

Sixteen years later, limited mouth opening $(12 \mathrm{~mm})$ was found on clinical examination, with limited lateral $(2 \mathrm{~mm}$ right and left) and protrusive excursions $(1 \mathrm{~mm})$. The patient had a second class normal occlusion, without open bite (figure 2).

\section{INVESTIGATIONS}

In both cases, patients underwent a dynamic CT scan with threedimensional (3D) reconstruction.

The first patient's images showed a $2 \mathrm{~cm}$ bony mass connecting the right coronoid process to the zygomatic bone and a posteriorly displaced right condylar process (figure 3 ).

The second patient's scans showed a bony mass connecting the right coronoid process to the squama temporalis (figure 4).

Dynamic scans can be helpful when investigating the continuity relationship between dynamic structures.

We performed histopathological examination on the two coronoidectomy bony specimens. In both cases the specimen was composed of cancellous bone, whose characteristics were comparable to normal compact bone without signs of neoplastic growth.

\section{TREATMENT}

\section{Case A}

The patient underwent surgery under general anaesthesia. A bilateral mucosal incision over the external oblique ridge was

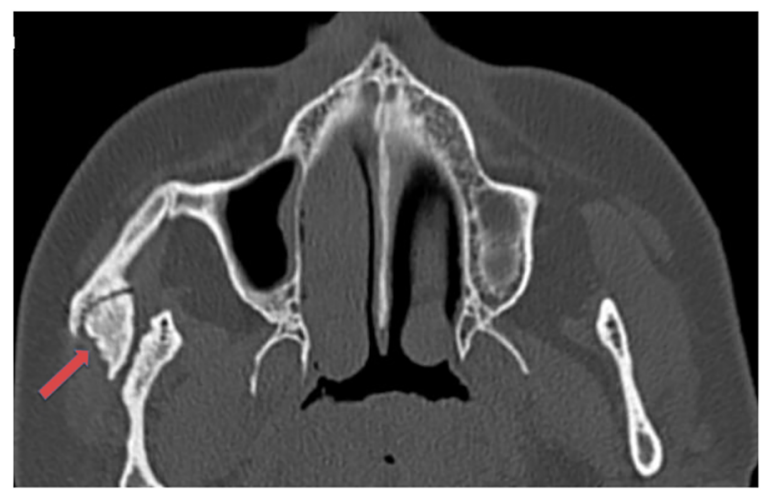

Figure 3 Patient A: preoperative CT scan. This axial image shows the ankylotic block (arrow) which connects the right coronoid process to the zygomatic bone.

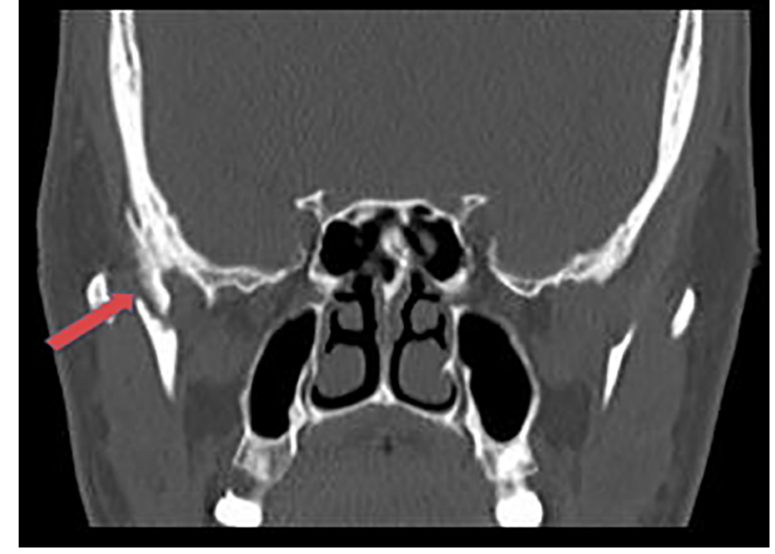

Figure 4 Patient B: preoperative CT scan. This coronal image shows the ankylotic block (arrow) which connects the coronoid process to the squama temporalis.

performed and soft tissues were dissected to expose the coronoid process bilaterally. On the right side, a fibro-osseous lesion connecting and surrounding the coronoid process was removed (figure 5). Both temporalis muscle tendons were detached from the coronoid processes. Bilateral coronoidectomy and forced opening of the mouth were performed to obtain maximal mouth opening. The incisions were sutured in one layer with absorbable suture. At the end of surgery, an intraoral wedge was positioned to induce maximal mouth opening and was maintained for 10 days. The postoperative course was uneventful. The patient underwent postoperative physiotherapy with a 'butterfly' orthodontic device for 2 months.

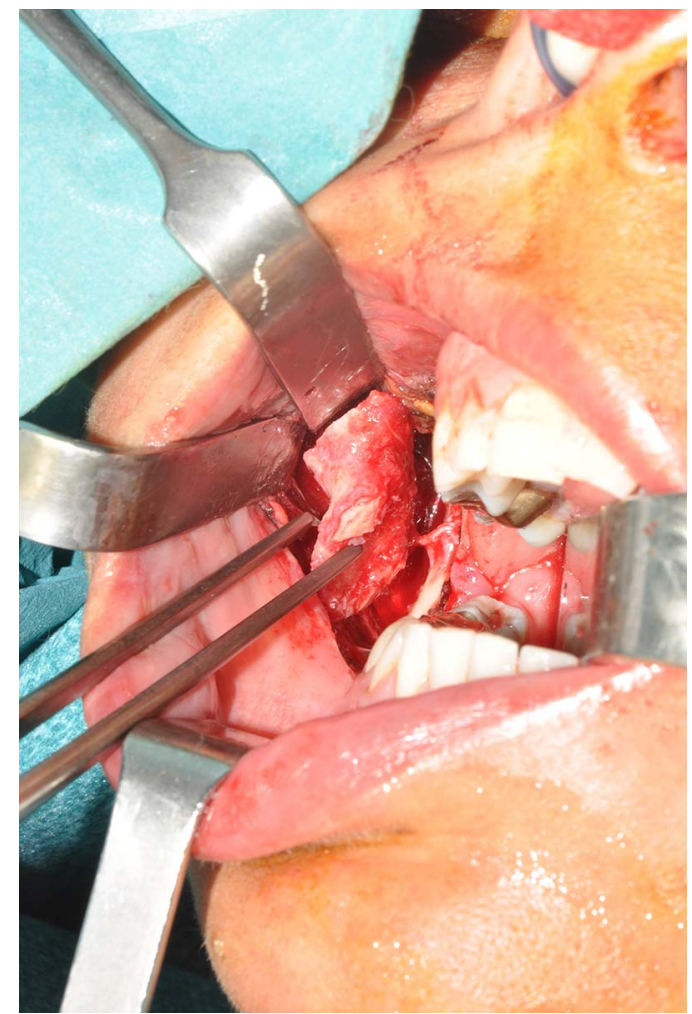

Figure 5 Intra-operative photograph. The ankylotic block has been completely mobilised and is ready for removal through and endoral access. 


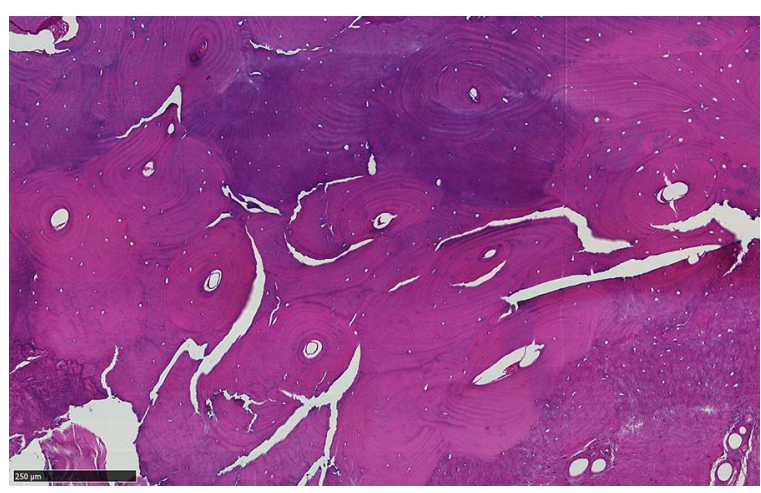

Figure 6 Histopathological examination showed that the specimen was composed of cancellous bone, whose characteristics were comparable to normal compact bone without signs of neoplastic growth.

\section{Case B}

The patient underwent surgery under general anaesthesia. An intraoral incision over the external right oblique ridge was performed. Another coronal incision was performed to expose the coronoid process and the bony block. A right zygomatic osteotomy (between the coronoid process and the squama temporalis) was performed to excise the ankylotic mass (figure 6). A left intraoral coronoidectomy was performed through mucosal access over the oblique external ridge. At the end of surgery, the mouth was forced open to a $46 \mathrm{~mm}$ interincisal distance (figure 7). The

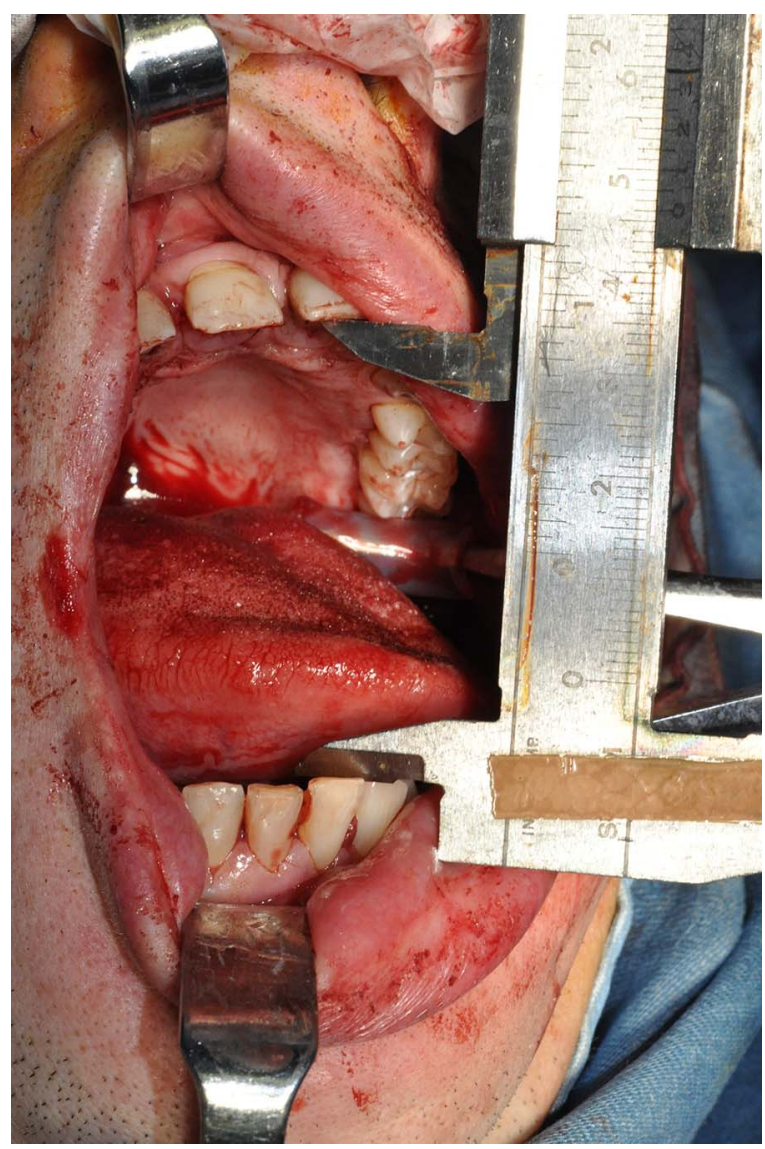

Figure 7 Patient B: intraoperative photograph. The photograph depicts a $46 \mathrm{~mm}$ forced maximal interincisal opening at the end of surgery. intraoral incisions were sutured with one-layered relapsable suture, while the cutaneous incision was sutured with a twolayered relapsable-non-relapsable suture. An intraoral wedge was placed to maintain mouth opening for the first week after surgery. The postoperative course was uneventful.

The patient underwent postoperative physiotherapy with a helicoidal mouth opener for 3 months.

\section{OUTCOME AND FOLLOW-UP \\ Case A}

Twelve months after surgery, a 3D CT scan and orthopantomography confirmed the absence of relapse. Physical examination showed a $32 \mathrm{~mm}$ interincisal mouth opening with no lateral deviation. Protrusive and lateral movements were restored (10 $\mathrm{mm}$ right and left, $7 \mathrm{~mm}$ of protrusion) (figures 8 and 9).

\section{Case B}

Six months after surgery, physical examination showed a $34 \mathrm{~mm}$ interincisal mouth opening. Protrusive and lateral movements were restored ( $9 \mathrm{~mm}$ right and left, $6 \mathrm{~mm}$ of protrusion). The patient was instructed to exercise five times a day with the mouth opener to maintain a wide interincisal distance. Low patient compliance coupled with a lack of regular mouth exercise explained the reduction in the interincisal opening $(24 \mathrm{~mm})$ 12 months after surgery (figure 10). A postoperative CT scan and orthopantomography showed no relapse of ankylosis.

\section{DISCUSSION}

There are different types of false ankylosis. For example, the coronoid process may fuse with the temporal bone, zygomatic arch or maxillary bone. Multiple causes of extracapsular ankylosis have been reported in the literature, including the development of intracapsular ankylosis anteriorly joining the sigmoid notch to the zygomatic arch and skull base, trauma, infection and iatrogenic causes. ${ }^{13}$

Tissue between bones can be fibrous ${ }^{3}$ or osseous, with identical signs and symptoms but different pathogeneses. Haematomas caused by trauma or arising during corrective surgery may develop in fibrous tissue. This tissue binds the coronoid bones to the bony structure surrounding the infratemporal fossa. The temporalis and masseteric muscles are liable to contusion. We assume that development of ankylosis is a gradual process. Initially, fibrous tissue restricts mandibular movement, and is soon replaced by fibro-osseous tissue. ${ }^{7}$ The ankylosis can be treated early with forced mouth opening. ${ }^{3-5} 7$

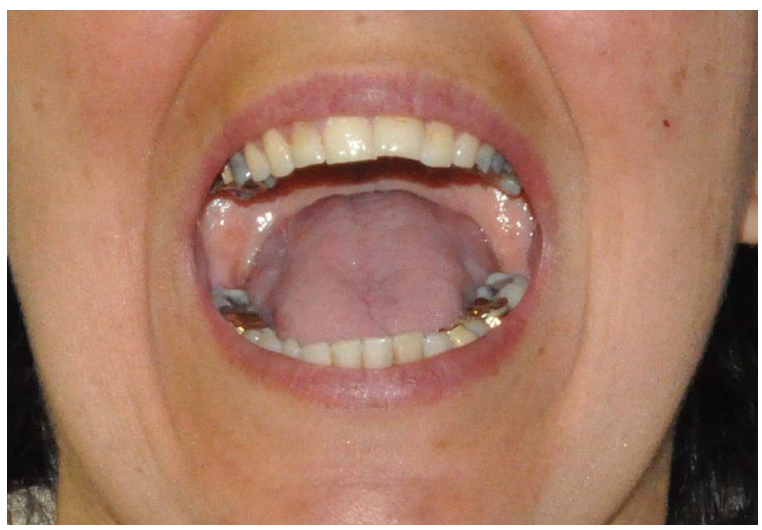

Figure 8 Patient A: 1-year follow-up photograph. The image shows a $32 \mathrm{~mm}$ maximum interincisal mouth opening with no lateral deviation. 


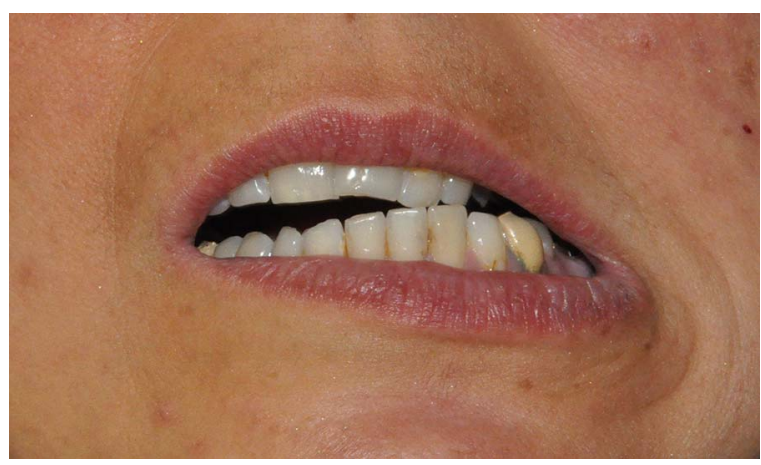

Figure 9 Patient A: 1-year follow-up photograph. The image shows restored contralateral movement.

Diagnosis of this type of pseudoankylosis was challenging before the introduction of CT scans with 3D reconstruction.

Pseudoankylosis may be approached surgically (intra- or extraoral approaches to coronoidectomy to restore jaw movements) or non-surgically. Extraoral approaches include hemicoronal incision, submandibular approaches and preauricular incision. The intraoral approach requires an incision over the external oblique ridge to reach the coronoid process and perform a coronoidectomy with resection of the ankylotic block segment. Thoma considers this technique the gold standard in treating ankylosis because it is conservative and there are no visible scars. ${ }^{14}$ The intraoral approach is less traumatic and less likely to injure the facial nerve. ${ }^{15-17}$ Extraoral approaches should be limited to those cases where intraoral ankylotic block removal is unsuccessful. During the same surgical procedure, wider surgical exposure allows for more convenient manoeuvres.

In our opinion, the best surgical treatment is a bilateral coronoidectomy with sectioning and removal of the bony ankylotic mass and both coronoid processes. We remove both coronoid processes so that mouth opening is not hindered by left temporal muscle fibrotic metaplasia. ${ }^{17}$

Rikalainen et al suggest strenuous supervised physiotherapy to prevent pseudoankylosis. ${ }^{5}$ Physiotherapy must follow all surgical treatment in order to maintain or, hopefully, increase mouth opening and preserve the mouth movements obtained after surgery. ${ }^{7}$ Many authors have proposed postoperative physiotherapy, but there is no consensus about timing. ${ }^{18}$

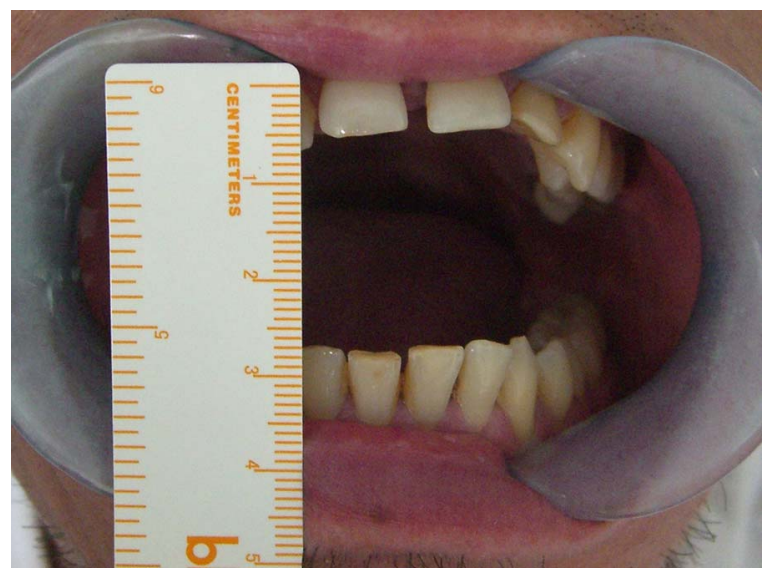

Figure 10 Patient B: 1-year follow-up photograph. The image shows a $24 \mathrm{~mm}$ maximum interincisal mouth opening.
Vanhove and Dom suggest physiotherapy once a day during the first 2 weeks after surgery and once every 2 days for the following 2 weeks. ${ }^{19}$ Warson recommends stretching exercises starting from $24 \mathrm{~h}$ after surgery and continuing for 6 months. ${ }^{20}$ Ostrofsky and Lownie encourage postoperative active physiotherapy using a spring exerciser. ${ }^{16}$ There is a general consensus among authors on the need to start aggressive physiotherapy immediately after the surgical procedure in order to ensure the best functional results. ${ }^{10} 11$

Williams et al applied a rubber prop for $7 \mathrm{~h}$ immediately after forced opening of the mouth to maintain the open position. ${ }^{21}$ The patient was then placed on a regimen of exercises to prevent recurrent ankylosis. Allison et al also suggest the use of a mouth prop. ${ }^{17}$ We positioned a mouth prop to maintain the mouth opening obtained at the end of surgery. Patients used it overnight for the first 10 days after surgery. A 2-month physiotherapy regimen with a butterfly device was then prescribed for patient A. Patient B was prescribed daily exercises with a helicoidal mouth opener, but exercises were seldom performed, with limited compliance, preventing any further widening of the mouth opening.

\section{Learning points}

- Surgical removal of the fibro-osseous block is the treatment of choice for pseudoankylosis of the jaw.

- The intraoral approach is seldom sufficient to remove the ankylotic mass so a second temporal surgical route is generally necessary to better control the temporal region and the zygomatic arch.

- Postoperative physiotherapy ensures the maintenance of adequate mouth opening over time, improving postsurgical results.

Acknowledgements We thank the two professional editors, both native speakers of English, who checked the English in this document.

Contributors VB and FA followed up the patients, FB operated on the patients and LM performed histopathological investigations.

Competing interests None declared.

Patient consent Obtained.

Provenance and peer review Not commissioned; externally peer reviewed.

\section{REFERENCES}

1 Nwoku AL, Kekere-Ekun TA. Congenital ankylosis of the mandible. Report of a case noted at birth. J Maxillofac Surg 1986;14:150-2.

2 Rottke B, Dunker R. Ein Beitrag zu den Spaetfolgen unbehandelter Frakturen im Jochbogenbereich. Fortschr Kiefer Gesichtschir 1967;12:123-5.

3 Schwartz HC, Kagan AR. Zygomatic-coronoid ankylosis secondary to heterotopic bone formation: combined treatment by surgery and radiation therapy: a case report. J Maxillofac Surg 1979;7:158-61

4 Super S, Cotton JS Jr. Bilateral pseudoankylosis of the temporomandibular joint to synostoses between the mandible and maxilla. J Oral Maxillofac Surg 1982:40:590-2.

5 Jain G, Kumar S, Rana AS, et al. Temporomandibular joint ankylosis: a review of 44 cases. Oral Maxillofac Surg 2008;12:61-6.

6 Gundlach KKH. Ankylosis of the temporomandibular joint. J Craniomaxillofac Surg 2010;38:122-30.

7 Rikalainen R, Lamberg MA, Tasanen A. Extra-articular fibrous ankylosis of the mandible after zygomatic fracture. J Maxillofac Surg 1981;9:132-6.

8 Erol B, Tnrikulu R, Gorgun B. A clinical study on ankylosis of the temporomandibular joint. J Craniomaxillofac Surg 2006;34:100-6.

9 Miller GA, Page HL Jr, Griffith CR. Temporomandibular joint ankylosis: review of the literature and report of two cases of bilateral involvement. J Oral Surg 1975;33:792-803. 
10 Baraldi CE, Martins GL, Puricelli E. Pseudoankylosis of the temporomandibular joint caused by zygomatic malformation. Int J Oral Maxillofac Surg 2010;39:729-32.

11 Spijkervet FK, de Bont LG, Boering G. Management of pseudoankylosis of the temporomandibular joint: report of cases. J Oral Maxillofac Surg 1994;52:1211-17.

12 Longobardi G, Boniello R, Gasparini G, et al. A new 3-phase therapy protocol in temporomandibular joint ankylosis: our experience. J Craniofac Surg 2009:20:483-7.

13 Topazian RG. Comparison of gap and interposition arthroplasty in the treatment of temporomandibular joint ankylosis. J Oral Surg 1966;24:405-9.

14 Thoma KH. Oral surgery. St Louis: C.V. Mosby, 1963:606, 608-609.

15 Marlette RH. Trismus and pseudoankylosis resulting from a coronoid-zygomaticmaxillary fusion: report of a case. J Oral Surg Anesth Hosp Dent Serv 1963;21:156-162.
16 Ostrofsky MK, Lownie JF. Zygomatico-coronoid ankylosis. J Oral Surg 1977;35:752-4.

17 Allison ML, Wallace WR, Von Wyl H. Coronoid abnormalities causing limitation of mandibular movement. J Oral Surg 1969;27:229-33.

18 Marimuthu K, Murton AJ, Greenhaff PL. Mechanisms regulating muscle mass during disuse atrophy and rehabilitation in humans. J Appl Physiol 2011;110:555-60.

19 Vanhove F, Dom M. Zygomatico-coronoid ankylosis: a case report. Int J Oral Maxillofac Surg 1999;28:258-9.

20 Warson RW. Pseudoankylosis of the mandible after a fracture of the zygomaticomaxillary complex: report of a case. J Oral Surg 1971;29:223-4.

21 Williams AC, Phillips $H$, Rothman $B$, et al. Ankylosis of the coronoid process to the zygomatic arch and maxilla: report of case. J Oral Surg 1968;26:804-6.

Copyright 2015 BMJ Publishing Group. All rights reserved. For permission to reuse any of this content visit http://group.bmj.com/group/rights-licensing/permissions.

BMJ Case Report Fellows may re-use this article for personal use and teaching without any further permission.

Become a Fellow of BMJ Case Reports today and you can:

- Submit as many cases as you like

- Enjoy fast sympathetic peer review and rapid publication of accepted articles

- Access all the published articles

- Re-use any of the published material for personal use and teaching without further permission

For information on Institutional Fellowships contact consortiasales@bmjgroup.com

Visit casereports.bmj.com for more articles like this and to become a Fellow 